\title{
Skewness of the Volatility Smile and Stock Returns in Brazil
}

\author{
Cristina Pimenta Luz ${ }^{1}$, Antonio Carlos Figueiredo Pinto ${ }^{1} \&$ Marcelo Cabus Klotzle ${ }^{1}$ \\ ${ }^{1}$ Pontifical Catholic University of Rio de Janeiro, Brazil \\ Correspondence: Marcelo Cabus Klotzle, Pontifical Catholic University of Rio de Janeiro, Brazil. E-mail: \\ klotzle@iag.puc-rio.br
}

Received: November 2, 2014

Accepted: November 19, 2014

Online Published: December 25, 2014

doi:10.5539/ibr.v8n1p173

URL: http://dx.doi.org/10.5539/ibr.v8n1p173

\begin{abstract}
Several studies suggest implied volatility and options trading volume as a proxy for risk analyses and forecast returns. The skewness of the volatility smirk also appears in this field. Xing, Zhang and Zhao (2010) demonstrated the effect of this skew on the stock returns in the U.S. market and attempt to explain the results by the activity of inside traders. Using the conclusions of this study as a starting point, we sought to assess its individual validity on a daily level for the two principle shares traded on BM\&FBovespa, using the implied volatility skew as an external regressor in the AR-GARCH models for shares returns. The results showed predictable gains of the models with skew, but the effect, however, was varied according to company, in accordance with the time lag of the regressor. It is possible to say that the options market in Brazil contains information about future returns; however, this connection appears, initially, to be specific to each company.
\end{abstract}

Keywords: predictability of returns, skew of implied volatility, volatility smirk

\section{Introduction}

Predictability of returns and, consequently, risk management are two constant concerns in the financial markets. One central factor for both these questions is the incorporation of information to the pricing of assets. Easley and O'Hara (1987), Easley, O'Hara and Srinivas (1998), Anand, Chakravarty and Martell (2005), Kaniel and Liu (2006) study the activity of traders with insider information in the markets and the consequences on asset trading.

Easley, O'Hara and Srinivas (1998) outline, in particular, the operating market of these traders in light of the type of the underlying information and show that the traded volume in the options market can be informative for future movement of shares. Pan and Potesham (2006) backup the evidence. Xing, Zhang and Zhao (2010) examine the question further when relating the volatility smirk, by defining a measurement of skewness, to the future returns of shares, aiming to forecast possible negative returns.

Despite the low liquidity of the Brazilian options market, it represents an alternative to hedge of positions and speculation. Yoshino (2003) shows the information contained in implied volatility of ATM options (in-the-money) and ITM (in-the-money) of the Bovespa index before the 1997 Asian Crash. In this study, he confirms the presence of the volatility smirk and points to ATM options as forecasters of the crash and ITM as representative of speculation. Vicente and Guedes (2010) show the influence of implied volatility of Petrobras OTM options (out of the money) on future volatility.

From Xing et al.'s (2010) work, this study attempts to intensify the investigation into the power of the information contained in the volatility smirk over options with larger liquidity on the Brazilian market, which are, options on Vale (VALE5) and Petrobrás (PETR4) shares. The focus is to verify to what extent the hypothesis that a strongly skewed volatility smirk indicates low return is supported, relative to daily data, and if this relationship between the skewness and return may help risk management. Therefore, the time series was modeled for returns of both the shares with AR-GARCH models and, subsequently, the skewness of the implied volatilities of the options was included as external regressors. The data used was from 2005 to 2011.

The first part of this article introduced the topic. The next part complements the review of the bibliography on the relationship between the options and stocks markets and introduces the review of the time series modeling and volatility skew. The third part details the database used and the fourth presents the model and the adjusted results obtained. The fifth part presents the conclusion and suggests future analyses. 


\section{Review of the Literature}

Risk management in financial markets is the focus of constant attention, both at the level of ordinary administration of positions, and at the extraordinary level relevant to the imminence of "crashes" or strong devaluation of the market, sectors and even individual companies. Battes (1991) shows the OTM stock options (out of the money) before and after the market crash in October 1987 signaled the expectance of a recession. He argued that the OTM put options on the S\&P 500 index became extremely expensive in the previous years, when compared to the respective call options and, upon constructing a jump diffusion model, identifies the negative skew in the distribution of the price of options, not compatible with the B\&S models (BLACK; SCHOLES, 1973) and GARCH. Chen, Hong and Stein (2001) conducted several regressions to forecast skewness of the price of individual stocks as a proxy of "bubbles" and show the variation in the implied volatility of OTM put options when considering the past negative skew of the stocks in their pricing.

The existence of skew and kurtosis in the distribution of share returns and the relationship with the volatility smirk is studied by Bakshi, Kapadia and Madan (2003), in particular, when differentiating the response of individual shares and the market index. They attempt to precisely recover the neutral skewness from the smirk observed and conclude, together with others, that the shares with the most negative skew possess a more accentuated smirk. Furthermore, it is possible to identify the skew of the volatility smirk as reflecting the neutral distribution of skew and kurtosis to the risk of returns, consistent with the theory that the options market responds to the stock market's aversion to risk.

Conrad, Dittmar and Ghysels (2013), from the Bakshi et al. (2003) study and the supposition that the options and stock markets contain the same information, believe the higher moments (skew and kurtosis) of probability distribution neutral to the risk of future returns from the implied moments in options with correspondent maturity and conclude that the moments are significant in forecasting future returns, in particular, the skew possesses a strong inverse connection to the returns.

Along the same lines, Chang, Christoffersen and Jacobs (2013) extract volatility, implied skew and kurtosis in options from the S\&P 500 index (market portfolio) and determine innovation measurements for each of those moments. The result obtained is that shares with more exposure to innovation in market skew have, on average, lower returns. Furthermore, they observe that the premium of the skew risk possesses economical and statistical significance.

Cao, Yu and Zhong (2010), when studying the relation between credit default swaps (CDS) with the implied volatility of out-of-the-money put options conclude that this dominates the historical volatility when explaining the CDS spreads. They also observe that the lower the skew of the implied volatility, seen as a proxy of the share return skew, the larger the probability of default and the spread of CDS.

In addition to studies of the information contained in higher moments of returns distributions, it is possible to find studies which attempt to explain the origin of these information. Easley and O'Hara (1987), in turn, show the preference of these traders to operate large volume, regardless of price, which limits the price strategies to the size of the operations. Easley et al. (1998) return the focus to the insider traders' market and construct a model of skew information to verify the consequences on the stock market in situations where these traders prefer to operate on the options market. Thus, they identify that the traded volume of certain options leads to variations in share prices. Pan and Patesham (2006) confirm this evidence and examine the connection even further to show that shares with less ratio among put and call options, initiated by buyers, surpass shares with a larger ratio. The explanation is based on traders with non-public information and the capacity for hard forecast for a few weeks due to the time it takes for the information to be absorbed by the market.

Additionally, the equilibrium model of Gârleanu, Pedersen and Poteshman (2009) shows the effect of the pressures of demand for options on their prices in an imperfect scenario of equilibrium among the operators and final users. Empirical application attested that implied volatility skew is positively correlated to the skewness of demand for options by final users, just as the price of options is correlated to the demand of final users, in that the relation is proportionally larger when the market is less active.

Consistent with the Gârleanu et al. (2009) model and the observations of Pan and Poteshman (2006), Xing et al. (2010) argue that in light of the perspective of strong market lows, well informed traders increase the demand for out-of-the-money put options, which in turn generates an increase in implied volatility skew, presently defined as the difference between implied volatility of out-of-the money put options and in-the-money call options (skew). Xing et al. (2010) go on to test this skew as a forecaster of low shares returns and conclude that shares with more skew in the volatility smirk get results, on average, $10 \%$ worse that shares with less skew and that this predictability lasts up to six months. 
Rehman and Vilkov (2012) review the theory and the empirical studies regarding implied volatility skew and future returns and ascertain that regardless of models (MFIS), derived from Bakshi et al. (2003), implied skew is positively correlated to future returns. The result is explained by the asset pricing error and the process for correcting this pricing, in that the speed of MFIS variation is sensitive to the asset's arbitration risk. In this study, one of the control measures is skew as defined by Xing et al. (2010), which remains significant and negatively correlated to the return. However, the authors argue the preference for MFIS in that it represents the entire distribution as opposed to just two points as skew does.

In Brazil, Yoshino (2003) estimates the implied market risk to the implied in price of different options traded and constructs both the structure according the risk term as well as the surface of volatility. He discovers, furthermore, that before the 1997 Asian Crash, the implied volatility of in-the-money call options provided information regarding market speculation. Vicente and Guedes (2010) attempt to forecast the future share volatility from the implied volatility of options for the differing moneyness and historical volatility. The empirical study of the monthly data relevant to Petrobras showed that the implied volatility of out-of-the-money options is more informative than the historical volatility in this forecast and possesses a positive correlation, while the implied volatility for all other moneyness does not possess a statistically significant explanation.

In their analyses, the studies presented mainly use implied volatility calculated by the Black and Scholes (1973) model, which, in addition to being the most recognized approach, is supported on the Brazilian market by the work of Araújo et al. (2003) in that it results in lower price differences given by the model and the market.

Attempting to identify incorporation of information to the pricing of individual assets, it is also necessary to understand the dynamics of the time series of prices and returns. On the Brazilian market, Costa and Baidya (2001) analyze the statistical properties of the series of returns of the principle shares and identify stationary, leptokurtic distribution and dependence on time, as well as the inefficiency of the ARMA and GARCH models to model them. Silva (2009) concentrates his work on modeling volatility of the two principle shares traded in the country (PETR4 and VALE5) using heteroscedastic models with skewed volatility and obtains better adjustment with the EGARCH(1.1) model, showing a different response of the returns to "good" and "bad" news.

\section{Database}

In order to complete this study, the daily closing data of the VALE5 and PETR4 shares were collected from the historical base of the BM\&FBovespa, during the period from 01/03/2005 through 12/29/2011 (1731 trade days), as well as the call and put options for these shares, in addition to the pre-DI quotations for 1, 10, 30, 60, 90 and 180 days. Only the options with a minimum period of 1 week and maximum of 180 days to maturity were considered, in order to guarantee more liquidity.

From the data for options, and taking as a risk free rate the pre-DI index or rate obtained by its exponential interpolation for the option's maturity period, the implied volatility was calculated using the Black and Scholes (1973) formula for each option. After this, the average volatility calculated by the traded volume of in-the-money call options was calculated for each day $t$ and the company $I\left(V_{O L}^{A T M}\right)$ and that of the out-of-the-money put options $\left(V O L_{i, t}^{O T M}\right)$. The at-the-money (ATM) call options were considered as being those with a ratio between the strike price over the current price between 0.95 and 1.05 , while the out-of-the-money put options (OTM) were defined as those with a ratio between 0.80 and 0.95 , as adopted by Xing et al. (2010), Vicente and Guendes (2010) and Araújo et al. (2003). Due to lower liquidity of the market for put options, for those days on which were non-existent for the OTM classification of moneyness, the data concerning put options synthesized by the parity relation between Merton's (1973) call and put options was considered, validated by Klemkosky and Bruce (1979). Once the implied volatilities were obtained $V O L_{i, t}^{A T M}$ and VOL $L_{i, t}^{O T M}$ for the database, the inviability of the calculation for some days was attested, as quantified in Table1.

Table 1. Number of observations in the series

\begin{tabular}{|c|c|c|c|c|}
\hline & & $\mathrm{N}^{\circ}$ Observations & Missing data & \% Missing data \\
\hline \multirow{3}{*}{$\begin{array}{c}\text { Vale } \\
\text { (VALE5) }\end{array}$} & Closing price & 1731 & 0 & $0.00 \%$ \\
\hline & $V O L_{i, t}^{A T M}$ & 1730 & 1 & $0.05 \%$ \\
\hline & $V O L_{i, t}^{O T M}$ & 1640 & 91 & $5.25 \%$ \\
\hline \multirow{3}{*}{$\begin{array}{c}\text { Petrobras } \\
\text { (PETR4) }\end{array}$} & Closing price & 1731 & 0 & $0.00 \%$ \\
\hline & $V O L_{i, t}^{A T M}$ & 1730 & 1 & $0.05 \%$ \\
\hline & $V O L_{i, t}^{O T M}$ & 1706 & 25 & $1.44 \%$ \\
\hline
\end{tabular}


In order to fill in the unviable aspects of the calculation by adding to the series and preserving reliability, a completely random test (MCAR) was performed on the missing data for each company with the series: Closing price, $V O L_{i, t}^{A T M}$ and $V O L_{i, t}^{O T M}$. For both companies the test rejected $1 \%$ of the null hypothesis of the completely random data. Therefore, following Kofman and Sharpe's (2003) conclusions, the missing data was input using the EM algorithm (expectation-maximization), with the aid of the SPSS ${ }^{\circledR}$ program. With the complete series, the $S K E W_{i, t}$ was calculated for each day $\mathrm{t}$ and company i as a proxy of the volatility smirk of the options (XING; ZHANG; ZHAO, 2010):

$$
S K E W_{i, t}=V O L_{i, t}^{O T M}-V O L_{i, t}^{A T M}
$$

Since the focus of this study is returns, in addition to the VALE5 and PETR4 price series being non-stationary with the unit root (COSTA; BAIDYA, 2001; SILVA, 2009), the return logarithm of the $r_{i, t}$ shares was adopted as a variable to be modeled:

$$
r_{i, t}=\ln \frac{P_{i, t}}{P_{i, t-1}}
$$

where $\mathrm{P}_{\mathrm{i}, \mathrm{t}}$ is the closing price on day $t$ of the share of company $i$

In the calculation of returns from 09/01/2005 through 04/28/2008 for PETR4 and from 05/22/2006 through 09/03/2007 for VALE5, adjustment due to the stock split and earnings was performed. The time series return dealt with the return and skew and is presented in Figure 1 and their statistics in Table 2.

Table 2. Basic statistics of the return and SKEW series of the VALE5 and PETR4 stock from 2005 to 2011

\begin{tabular}{ccccccccccc}
\hline \multicolumn{2}{c}{$\mathbf{N}^{\mathbf{0}}$ obs. $=\mathbf{1 7 3 0}$} & Average & DP & Skew. & Kurt. & Min & $\mathbf{1}^{\mathbf{0}} \mathbf{Q}$ & $\mathbf{2}^{\mathbf{0}} \mathbf{Q}$ & $\mathbf{3}^{\mathbf{0}} \mathbf{Q}$ & $\mathbf{M a x}^{2}$ \\
\hline Vale & $r$ & $0.051 \%$ & 0.025 & -0.178 & 7.060 & -0.164 & -0.013 & 0.001 & 0.014 & 0.126 \\
$($ VALE5) & $S K E W$ & $4.152 \%$ & 0.024 & -0.141 & 7.377 & -0.199 & 0.005 & 0.035 & 0.070 & 0.483 \\
Petrobras & $r$ & $0.035 \%$ & 0.063 & 1.082 & 7.748 & -0.148 & -0.012 & 0.001 & 0.013 & 0.132 \\
$($ PETR4) & $S K E W$ & $4.573 \%$ & 0.068 & 2.420 & 28.070 & -0.406 & 0.009 & 0.038 & 0.072 & 0.960 \\
\hline
\end{tabular}

\section{VALE5}

- Logarithmic return

- $S K E W$



PETR4

- Logarithmic return

- $\quad S K E W$

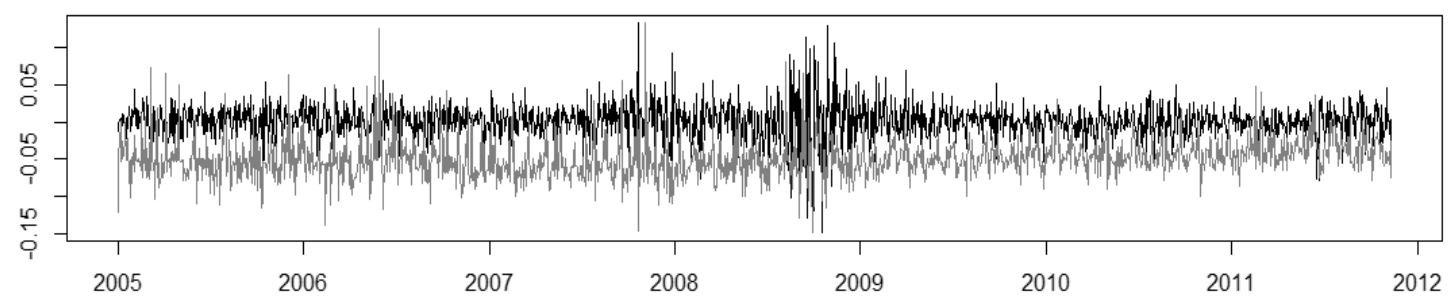

Figure 1. Time series of return and SKEW of the VALE5 and PETR4 shares from 2005 to 2011 


\section{Model and Results}

In order to test the explanatory and predictive capacity of skew regarding share returns, we opted to model the time series with an external regressor. Tsay (2010) recommends that the response series (dependent) be modeled first and the regressor (independent) included later. The work of Silva (2009) and Costa and Baidya (2001) demonstrates the presence of a unit root, GARCH effect, skew and kurtosis in the VALE5 and PETR4 price series, therefore, we tested the adequacy of different AR-GARCH and AR-GARCH models for the return series. The best adjustment obtained for VALE5 was an AR (3)-GARCH(1.1), with residual t-Student distribution with leverage and for PETR4, an AR(1)-GARCH(1.1) with null average and residual t-Student distribution with leverage. Figures 2 to 7 show the series'autocorrelation functions (ACF) and partial autocorrelation from the AR(3) model residues squared for the returns and the residues of the final model. Table 3 compares the models which obtained the best adjustment, in addition to the SKEW model.
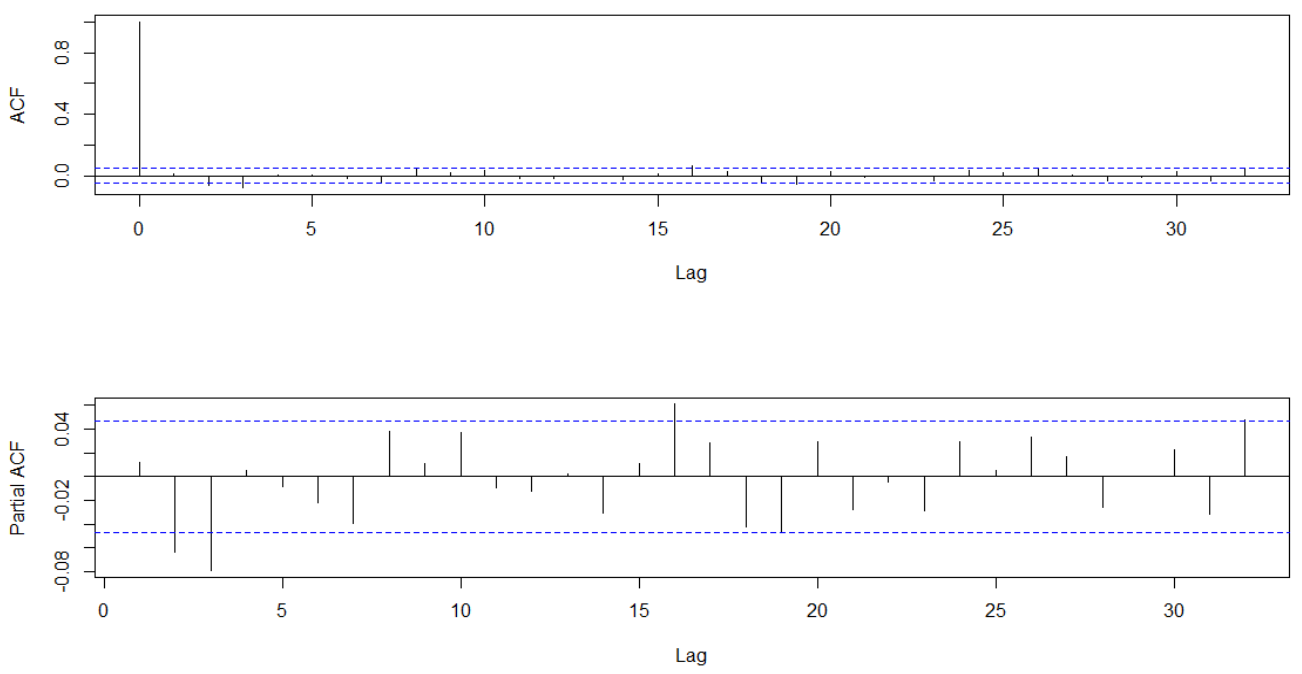

Figure 2. ACF and PACF of VALE5 returns
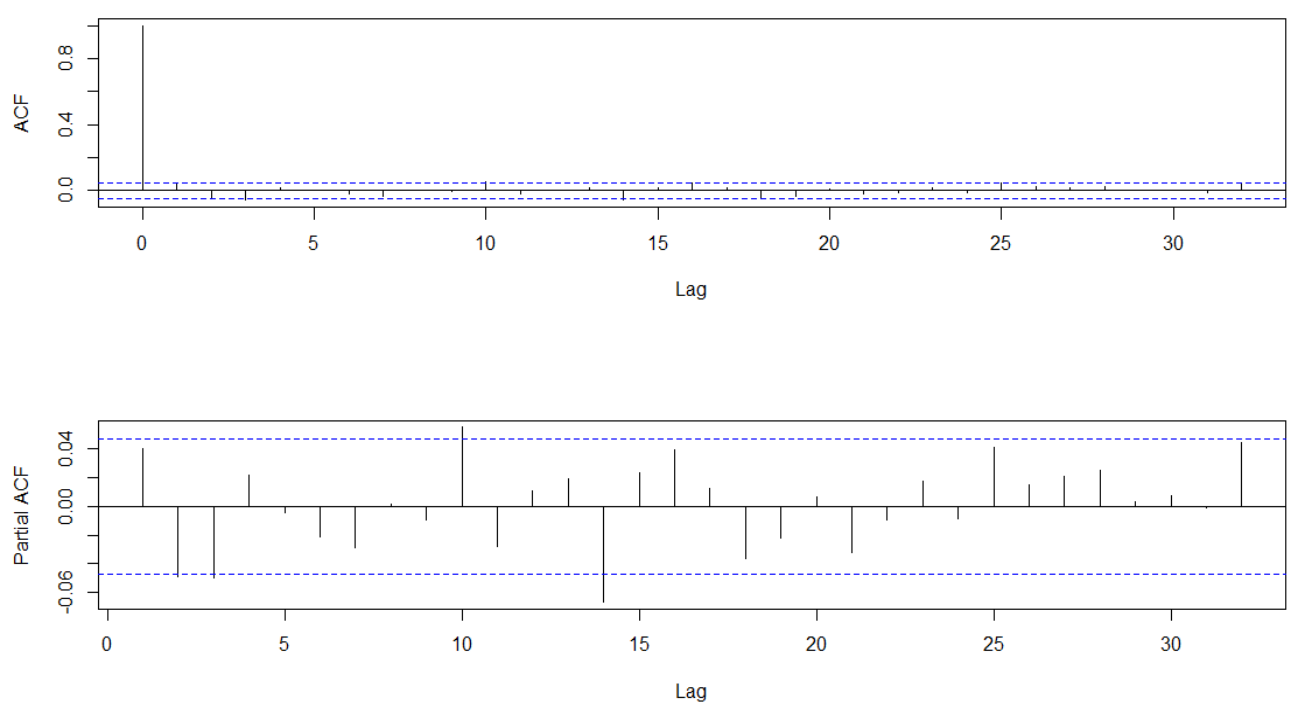

Figure 3. ACF and PACF of PETR4 returns 

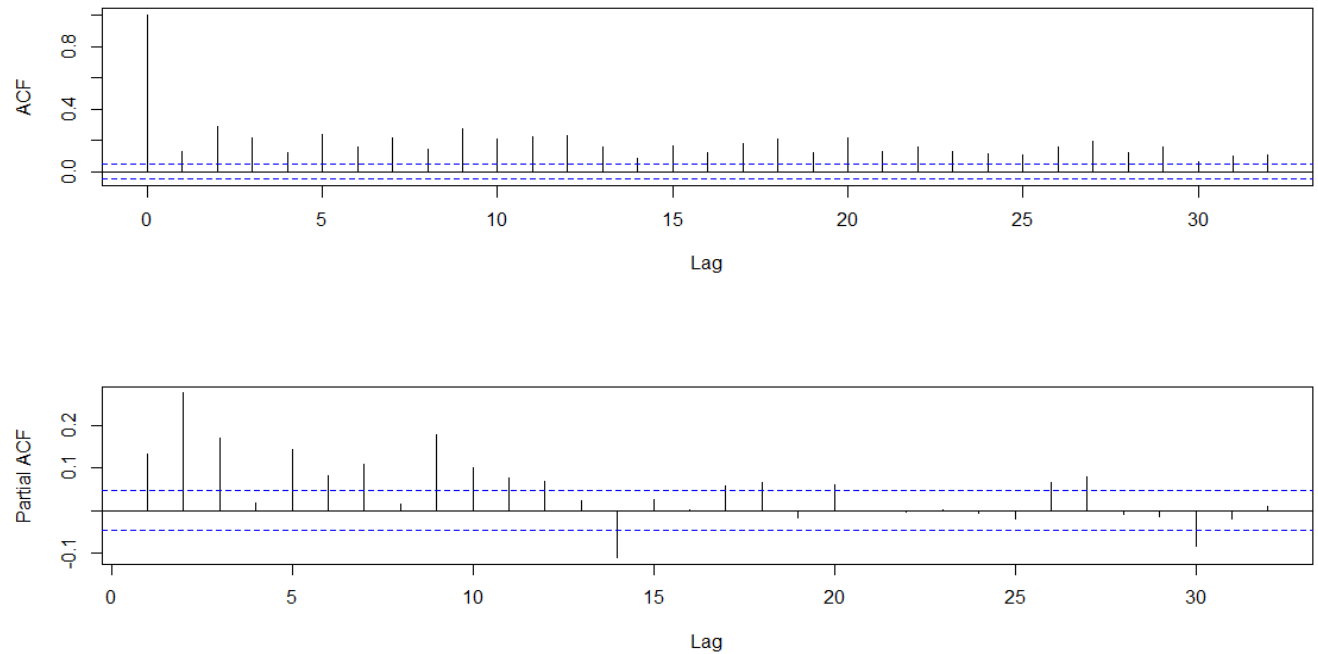

Figure 4. ACF and PACF of the square of the residues from the AR(3) model for VALE5


Figure 5. ACF and PACF of the square of the residues of the (3) model for PETR4

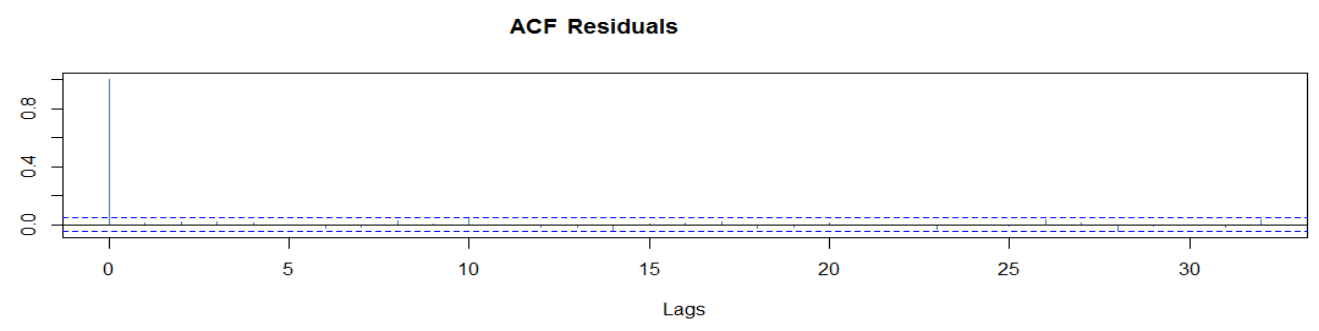

ACF Residuals^2

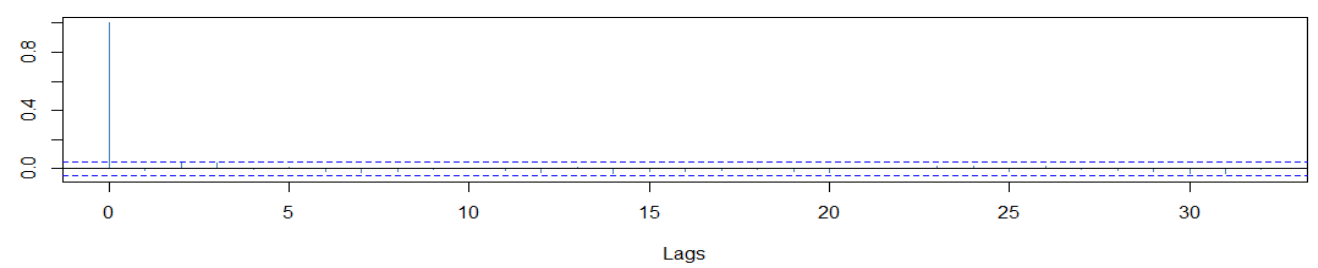

Figure 6. ACF of the residues and square of the residues from the AR(3)-GARCH(1,1) model for VALE5 

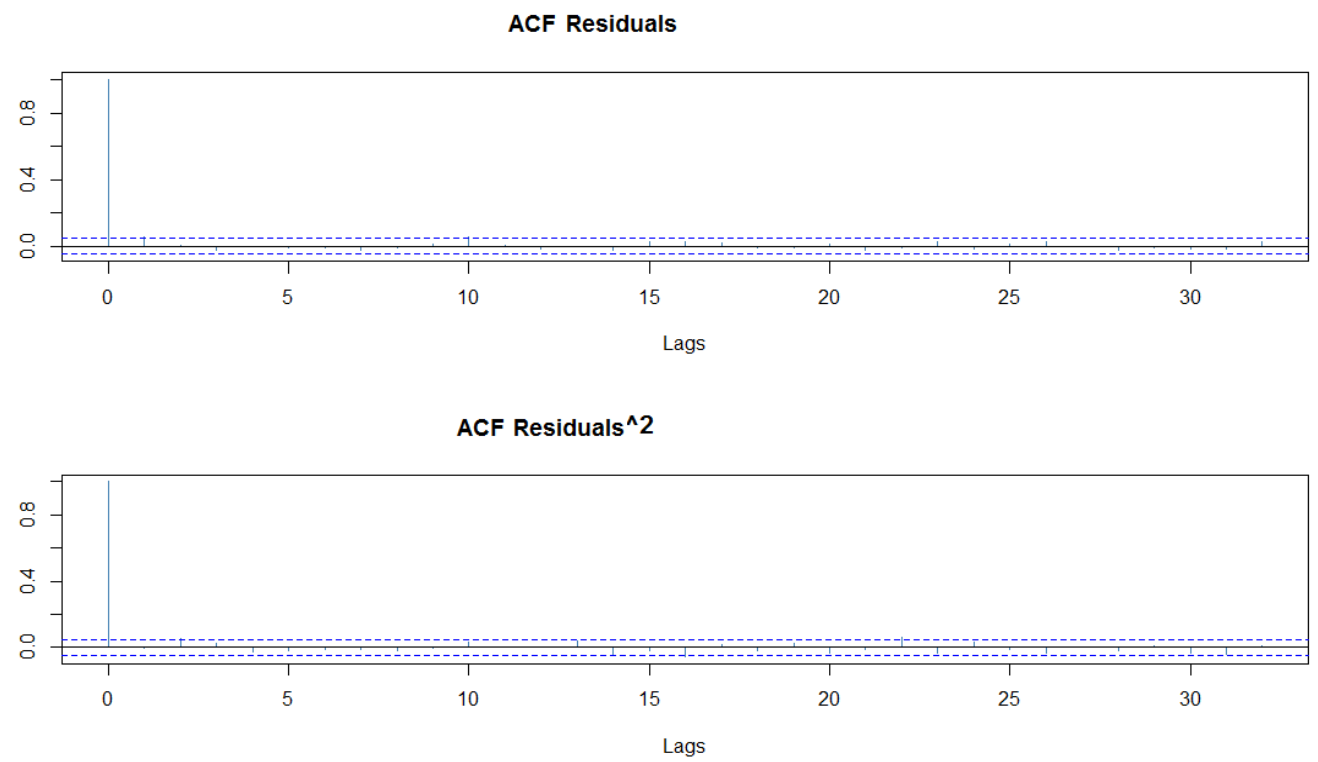

Figure 7. ACF of the residues and square of the residues from the AR(1)-GARCH(1,1) model for PETR4

Table 3. AIC and BIC information criterion of the models for the return from VALE5 and PETR4 (2005-2011)

\begin{tabular}{lcccc}
\hline \multirow{2}{*}{ Model | Series and information criterion } & \multicolumn{2}{c}{ Vale (VALE5) } & \multicolumn{2}{c}{ Petrobras (PETR4)* } \\
\cline { 2 - 5 } & AIC & BIC & AIC & BIC \\
\hline AR (3) & -7865.445 & & -7993.333 \\
AR(3)-GARCH(1,1) & -8286.296 & -8248.105 & -8481.430 & -8448.695 \\
AR(3)-GARCH(1,1) with t-Student & -8337.229 & -8293.582 & -8499.663 & -8461.472 \\
AR(3)-EGARCH(1,1) with t-Student & -8355.505 & -8306.402 & -8500.918 & -8457.271 \\
AR(3)-GARCH(1,1) with t-Student and leverage & $\mathbf{- 8 3 6 0 . 5 8 0}$ & -8311.477 & -8514.382 & -8470.735 \\
AR(1)-GARCH(1,1) with t-Student and leverage & -8355.172 & $\mathbf{- 8 3 1 6 . 9 9 1}$ & $\mathbf{- 8 5 1 7 . 3 0 3}$ & $\mathbf{- 8 4 8 4 . 5 6 8}$ \\
Model withSKEW (equations (3) and (4)) & $\mathbf{- 8 3 7 5 . 0 3 4}$ & $\mathbf{- 8 3 2 0 . 4 7 5}$ & $\mathbf{- 8 5 3 4 . 3 6 5}$ & $\mathbf{- 8 4 9 6 . 1 7 4}$ \\
\hline
\end{tabular}

*The models for PETR4 considered average null.

The best model for each series was chosen based on the Akaike criterion and over time was considered the best reference model. From the reference model, the SKEW series were included as an external regressor, maintaining the $\mathrm{t}-\mathrm{Student}$ distribution with leverage for the residues, in that:

$$
\begin{aligned}
& r_{\text {Vale }, t}=A R(3)-\operatorname{GARCH}(1,1)+S K E W_{\text {Vale }, t} \\
& r_{\text {Petr }, t}=A R(1)-\operatorname{GARCH}(1,1)+S K E W_{\text {Petr }, t}
\end{aligned}
$$

The adjustment of models (3) and (4) presented gains in relation to the information criterion and forecast for the returns, as well as having a significant skew coefficient of $1 \%$ for both series. The parameters and their p-values (below) are shown in equations (5) and (6). As predicted according to the study of Xing et al. (2010) the skew has an inverse effect on the returns, i.e., the larger the skew, the lower the expected return.

$$
\begin{aligned}
& \boldsymbol{r}_{\text {Vale }, t}=\underbrace{0,0022}_{0,000000}+\underbrace{0,0567}_{0,021} \times r_{\text {Vale }, t-1} \underbrace{-0,0390}_{0,10} \times r_{\text {Vale }, t-2} \underbrace{-0,0594}_{0,012} \times r_{\text {Vale }, t-3} \\
& \underbrace{\mathbf{- 0 , 0 3 1 9}}_{\mathbf{0 , 0 0 0 0 4}} \times S K E W_{\text {Vale }, t}+a_{\text {Vale }, t} ; a_{\text {Vale }, t}=\sigma_{\text {Vale }, t} \xi_{\text {Vale }, t} \\
& \sigma_{\text {Vale }, t}^{2}=\underbrace{0,00001}_{0,0004}+\underbrace{0,0762}_{0,00001} \times a_{\text {Vale }, t}^{2}+\underbrace{0,8915}_{0,000000} \times \sigma_{\text {Vale }, t-1}^{2} ; \quad \xi_{\text {Vale }, t} \sim t_{7,32 ; l e v=}=\underbrace{-0,38}_{0,0004}
\end{aligned}
$$




$$
\begin{gathered}
\boldsymbol{r}_{\text {Petr }, t}=\underbrace{0,0543}_{0,034} \times r_{\text {Petr }, t-1} \underbrace{}_{\underbrace{\mathbf{- 0 , 0 2 4 4}}_{\text {0,0001 }} \times S K E W_{\text {Petr }, t}}+a_{\text {Petr }, t} ; a_{\text {Petr }, t}=\sigma_{\text {Petr }, t} \xi_{\text {Petr }, t} \\
\sigma_{\text {Petr }, t}^{2}=\underbrace{0,00001}_{0,00004}+\underbrace{0,0759}_{0,0000009} \times a_{\text {Petr }, t}^{2}+\underbrace{0,8895}_{0,000000} \times \sigma_{\text {Petr }, t-1}^{2} ; \quad \xi_{\text {Vale }, t} \sim t_{12,98 ; \text { lev }=\underbrace{-0,36}_{0,0004}}
\end{gathered}
$$

To further understanding of the effect of skew and test its real contribution to forecasting, i.e., its prior record for forecasting returns variations, the constant and variable correlation models were adjusted for the return groups and skew of each share. After this, cross-autocorrelation of the residues was detected which was significant for some lags, which suggested durability of skew influence on returns, in particular for lag 24 (in the case of VALE5) and 23 (in the case of PETR4). Once the models were readjusted with the respective skew lags, as shown in equations $(7)$ and $(8)$, coefficients of -0.0190 ( $\mathrm{p}$-value $=0.0156)$ for Vale and +0.0155 ( $\mathrm{p}$-value $=$ 0.00734 ) for Petrobras were obtained.

$$
\begin{aligned}
& r_{\text {Vale }, t}=A R(3)-G A R C H(1,1)+S K E W_{\text {Vale }, t-23} \\
& r_{\text {Petr }, t}=A R(1)-G A R C H(1,1)+S K E W_{\text {Petr }, t-24}
\end{aligned}
$$

It is important to note that, due to the trading days, lags 23 and 24 represent the lag of approximately one month, a maturity interval for which there is more liquidity of options. Upon testing the forecasting capacity of models (7) and (8) in relation to the reference models for the different horizons, gains and losses were obtained when compared to the sum of the squared sum of the errors (SSE) forecast, as shown in Table 4. In the case of Vale, there was a gain in the forecast for shorter horizons (up to 30 days, while for Petrobras the gains were for longer

\begin{tabular}{|c|c|c|c|c|}
\hline \multirow{2}{*}{$\mathrm{N}^{\circ}$ of days forecast } & \multicolumn{2}{|c|}{ Vale (VALE5) } & \multicolumn{2}{|c|}{ Petrobras (PETR4) } \\
\hline & SSE Reference model & SSE Model with $S K E W$ lag & SSE Reference model & SSE Model with $S K E W$ lag \\
\hline 5 ( $\sim 1$ week) & 0.000845 & 0.000834 & 0.001268 & 0.001280 \\
\hline 10 & 0.002569 & 0.002546 & 0.003658 & 0.003625 \\
\hline 20 & 0.005476 & 0.005371 & 0.007525 & 0.007619 \\
\hline 30 & 0.007310 & 0.007257 & 0.010573 & 0.010656 \\
\hline 45 & 0.011582 & 0.011632 & 0.018831 & 0.018751 \\
\hline 60 & 0.022655 & 0.022949 & 0.025149 & 0.024811 \\
\hline
\end{tabular}
horizons (more than 45 days). Only for the 10 day horizon was there a gain for both series.

Table 4. Sum of the square of the errors for different horizons forecast from the reference models and SKEW lags for the returns of VALE5 and PETR4 (2005-2011)

The lag models were also significant for lags 15, 18, 35 (significant coefficients at 5\%), 5 and 10 (significant coefficients at 10\%) in the case of Vale and for lags 8 (significant coefficient at 5\%) and 16 (significant coefficient at 10\%) in the case of Petrobras. One relevant point of these models is that for Petrobras the skew lag coefficient is always positive, contrary to the first expectation, but supported by Rehman and Vilkov (2012).

In the case of Vale, the coefficient is positive only for lag 35 . One possible explanation for this difference can be obtained through observation of the basic statistics of the skew series. The Petrobras skew distribution possesses skew and kurtosis significantly more relevant than that of Vale; in addition to the Petrobras skew being positive while being negative for Vale. Thus, elevated skew values are recurrent in the Petrobras series, which may reduce variations sensitivity.

To understand better the origin of the explanatory capacity of skew, adjustments were made to the reference models with $V O L^{O T M}$ and $V O L^{A T M}$ as external regressors. For Vale, both implied volatilities were significant and improved the information criterion of the models compared to the model with skew, in particular, the model with $V O L^{O T M}$. In the case of Petrobras, only the model with $V O L^{O T M}$ is significant, however, at $10 \%$, it renders the information criterion lower than those obtained previously. Therefore, it appears that the effect of skew in the case of Vale is a consequence of the relation to the individually implied volatility, while for Petrobras, the relevance of skew is direct. The results of the adjustments are shown in Table 5. 
Table 5. Result of the models with implied volatility as an external regressor for VALE5 and PETR4

\begin{tabular}{lcccc}
\hline \multirow{2}{*}{ Result | Model } & \multicolumn{2}{c}{ Vale (VALE5) } & \multicolumn{2}{c}{ Petrobras (PETR4) } \\
\cline { 2 - 5 } & With $V O L^{\text {ATM }}$ & With $V O L^{\text {OTM }}$ & With $V O L^{\text {ATM }}$ & With $V O L^{\text {OTM }}$ \\
\hline Coefficient of VOL & -0.03758 & -0.04091 & -0.00126 & -0.00221 \\
Significance VOL & 3.55 and -14 & 0.00000 & 0.37450 & 0.06898 \\
AIC & -8405.415 & -8431.448 & -8515.974 & -8518.191 \\
BIC & -8350.856 & -8376.890 & -8477.783 & -8479.999 \\
\hline
\end{tabular}

\section{Conclusions}

The first conclusion obtained in this study is confirmation that from the daily perspective, skewness in the volatility smirk contains relevant information regarding future movements of the principle shares traded in Brazil. The directional of the information, however, is divergent. While the results obtained for Vale are supported by the relevant literature, for Petrobras, only the direct daily connection is supported. In other words. the higher the skew, the lower the return. For Vale, this relation seems to be valid for returns up to one month ahead. In the case of Petrobras, the skew seems to offer a directional with a longer period for returns, contrary to expectations, i.e., the higher the skew, the higher the expected return. This relation is also maintained for returns up to one month ahead.

Of the relations tested, it is possible to say that skew and $V O L^{O T M}$ are inversely correlated with the Vale returns, in that these have a higher explanation capacity. For Petrobras, only skew is able to explain the returns variations, being positively correlated on a day-to-day basis and negatively with the time lag.

Regarding the origin of the information contained in the skew, it is possible to say that for Vale, the implied volatility of options, in particular out-of-the-money options, increases with the expectation of lower returns and vice-versa, which may be explained by the relation of demand for options and its effect on prices and, consequently, on the implied volatility. In the case of Petrobras, the relevance of skew appears to be the result of the combined effect on the implied volatilities, be that due to an inverse relation of the demand-price or predominance of different maturities for each moneyness. A more in-depth study of the effect for different maturities is a possible method to elucidate these connections.

Moreover, it is clear that the options of both Vale and Petrobrás contain information about their future returns. This is backed by the literature in that it establishes different and, sometimes, contradictory relations between markets.

Xing, Zhang and Zhao (2010) present the hypothesis that traders with insider information prefer the options market when stock market lows are imminent, which would result in a higher skew. One suggestion for future studies is to verify if this hypothesis is ratified in Brazil when events with strong negative repercussions are analyzed as a whole or those of specific segments, for example, the electrical energy sector in 2012 after the MP $579 / 2012$ was announced in 09/12/2012, which resulted in falls above $30 \%$ in one day of activity in the sector.

\section{References}

Annand, A., Chajravarty, S., \& Martell, T. (2005). Empirical evidence on the evolution of liquidity: Choice of market versus limit orders by informed and uninformed traders. Journal of Financial Markets, 8, 289-309. http://dx.doi.org/10.1016/j.finmar.2005.03.001

Araujo G. S., Barbedo, C. H. S., Figueiredo, A. C., \& Lemgruber, E. F. (2003). Contornando os pressupostos de Black \& Scholes: Aplicação do Modelo de Precificação de Opções de Duan no Mercado Brasileiro. Banco Central do Brasil: Trabalhos para Discussão, 78, 1-30.

Bakshi, G., Kapadia, N., \& Madan, D. (2003). Stock Return Characteristics, Skew Laws, and the Differential Pricing of Individual Equity Options. The Review of Financial Studies, 16, 101-143. http://dx.doi.org/10.1093/rfs/16.1.101

Battes, D. S. (1991). The Crash of '87: Was It Expected? The Evidence from Options Markets. The Journal of Finance, 46, 1009-1044. http://dx.doi.org/10.2307/2328552

Black, F., \& Scholes, M. (1973). The pricing of options and corporate liabilities. Journal of Political Economy, 81, 637-59. http://dx.doi.org/10.1086/260062 
Cao, C., Yu, F., \& Zhong, Z. (2010). The information content of option-implied volatility for credit default swap valuation. Journal of Financial Markets, 13, 321-343. http://dx.doi.org/10.1016/j.finmar.2010.01.002

Chang, B. Y., Christoffersen, P., \& Jacobs, K. (2013). Market skewness risk and the cross section of stock returns. Journal of Financial Economics, 107, 46-68. http://dx.doi.org/10.1016/j.jfineco.2012.07.002

Chen, J., Hong, H., \& Stein, J. C. (2001). Forecasting crashes: trading volume, past returns, and conditional skewness in stock prices. Journal of Financial Economics, 61, 345-381. http://dx.doi.org/10.1016/S0304-405X(01)00066-6

Conrad, J. S., Dittmar, R. F., \& Ghysels, E. (2013). Ex Ante Skewness and Expected Stock Returns. Journal of Finance, 68, 85-124. http://dx.doi.org/10.1111/j.1540-6261.2012.01795.x

Costa, P., \& Baidya, T. (2001). Propriedades Estatísticas das Séries de Retornos das Principais Ações Brasileiras. Pesquisa Operacional, 21, 61-87. http://dx.doi.org/10.1590/S0101-74382001000100005

Easley, D., \& O’Hara. (1987). Price, trade size, and information in securities markets. Journal of Financial Economics, 19, 69-90. http://dx.doi.org/10.1016/0304-405X(87)90029-8

Easley, D., O'Hara, M., \& Srinivas, P. S. (1998). Option Volume and Stock Prices: Evidence on Where Informed Traders Trade. The Journal of Finance, 32, 431-465. http://dx.doi.org/10.1111/0022-1082.194060

Gârleanu, N., Pedersen, L. H., \& Poteshman, A. (2009). Demand-Based Option Pricing. The Review of Financial Studies, 22, 4259-4299. http://dx.doi.org/10.1093/rfs/hhp005

Kaniel, R., \& Liu, Y. (2006). So What Orders Do Informed Traders Use? Journal of Business, 79, 1867-191. http://dx.doi.org/10.1086/503651

Klemkosky, R. C., \& Bruce, G. R. (1979). Put-Call Parity and Market Efficiency. The Journal of Finance, 34, 1141-1155. http://dx.doi.org/10.2307/2327240

Kofman, P., \& Sharpe, I. G. (2003). Using Multiple Imputation in the Analysis of Incomplete Observations in Finance. Journal of Financial Econometrics, 1, 216-249. http://dx.doi.org/10.1093/jjfinec/nbg013

Merton, R. C. (1973). The Relationship between Put and Call Option Prices: Comment. The Journal of Finance, 28(1), 183-184. http://dx.doi.org/10.2307/2978180

Pan, J., \& Poteshman, A. M. (2006). The Information in Option Volume for Future Stock Prices. The Review of Financial Studies, 19, 871-908. http://dx.doi.org/10.1093/rfs/hhj024

Rehman, Z., \& Vilkov, G. (2012). Risk-Neutral Skewness: Return Predictability and its Sources. Retrieved from http://ssrn.com/abstract=1301648

Silva, C. (2009). Modelagem de Estimação da Volatilidade do Retorno das Ações Brasileiras: os casos da Petrobras e Vale. Cadernos do IME - Série Estatística, 26, 15-28.

Tsay, R. S. (2010). Analysis of financial time series (3rd ed.). New Jersey: John Wiley \& Sons.

Vicente, J. V. M., \& Guedes, T. S. (2010). A Volatilidade implícita contém informações sobre a volatilidade futura? Evidências do mercado de opções de ações da Petrobras. Brazilian Business Review, 7, 48-65. http://dx.doi.org/10.15728/bbr.2010.7.1.3

Xing, Y., Zhang, X., \& Zhao, R. (2010). What Does the Individual Volatility Smirk Tell Us About Future Equity Returns? Journal of Finance and Quantitative Analysis, 45, 641-662. http://dx.doi.org/10.1017/S0022109010000220

Yoshino, J. A. (2003). Market Risk and Volatility in the Brazilian Stock Market. Journal of Applied Economics, $6,385-403$.

\section{Copyrights}

Copyright for this article is retained by the author(s), with first publication rights granted to the journal.

This is an open-access article distributed under the terms and conditions of the Creative Commons Attribution license (http://creativecommons.org/licenses/by/3.0/). 